\title{
La poesía mitológica de Garcilaso de la Vega y la mayólica istoriata: un intento de perspectivas paralelas ${ }^{I}$
}

\author{
Roland BÉHAR \\ École Normale Supérieure-PSL, Paris
}

\begin{abstract}
El artículo se propone demostrar la utilidad y, quizás, la necesidad de tomar en cuenta un género de pintura del Renacimiento habitualmente poco considerado a la hora de reflexionar sobre el ut pictura poesis: la pintura sobre cerámica, más conocida como mayólica. Para ello, se recuerda el aprecio del que gozaban las mayólicas durante el Renacimiento, en la península italiana y fuera de ella, se describe la importancia de pintores como Nicolás de Urbino y Francesco Xanto Avelli -bajo la marcada influencia del magisterio de Rafael Sanzio-, y se detallan algunos puntos de contacto entre este arte de la mayólica y la poesía mitológica coeva, que halla sus modelos en Ovidio y en Petrarca. A modo de conclusión, dos ejemplos de sonetos mitológicos de Garcilaso de la Vega ofrecen ejemplos del interés que hay, también en España, en parangonar poesía y mayólica.
\end{abstract}

Keywords: Garcilaso de la Vega, Rafael Sanzio, Nicolás de Urbino, Ovidio, Francesco Petrarca.

I.

Sigue siendo un desiderátum de la investigación sobre el tópico de la picta poesis del Renacimiento una reseña sistemática de los tipos de imagen que sería posible acercar a su poesía desde una perspectiva diacrónica. Un simple ejemplo lo brindaría el caso del mito de Galatea y de las correspondencias entre poesía y pintura que lo representaron. En un reciente ensayo estudiamos las fuentes poéticas que pudieron animar a Garcilaso a elegir el nombre de Galatea para la pastora llorada por el Salicio de su Egloga I (Béhar 20I7a). Ahora bien, el poeta se corresponde claramente con aquella generación de pintores que difundieron la herencia visual de Rafael Sanzio por Italia y por toda Europa. Un paralelismo parecido se puede evidenciar para el desarrollo del lenguaje poético épico neoclásico, que se formula en la encrucijada entre pintura, escultura y poesía, que Garcilaso contribuye a formular en lengua castellana (Béhar 20I7b).

Al lado de la pintura o de los tapices, vistos o bien directamente o bien a través de su difusión masiva mediante los grabados, convendría también

I Deseo agradecer a Marie-Linda Ortega, quien me animó a reivindicar la importancia de un arte aparentemente inferior e injustamente postergado como lo puede ser la mayólica. 
considerar el papel del arte de la mayólica en la difusión de un imaginario a la vez preciso y generalizado de la mitología antigua. De hecho, no se suele evocar en relación con la poesía mitológica de Garcilaso, y eso a pesar de que, en muchas de sus características, la difusión de la mayólica se corresponde con la de los grabados, a los cuales se aventaja por su cromatismo y su lustre, adornando así los espacios interiores de la aristocracia de gusto italianizante del Cinquecento. En el paralelismo cuyo bosquejo se propone en lo que sigue, pero que merecería un estudio más demorado, conviene recalcar el que se produce, en la poesía como en la mayólica, una fuerte inflexión del gusto hacia materias mitológicas inspiradas en una Antigüedad cada vez más reivindicada por los artistas del Renacimiento.

Cierto es que la España del siglo xv había sido el lugar de una producción riquísima de cerámicas, con motivos hispanomoriscos o heráldicos, de raigambre musulmana, especialmente en el reino de Valencia, con los famosos talleres de Manises. Desde allí, se había difundido de modo masivo por el conjunto de las tierras de la corona de Aragón, las Baleares -de ahí, de hecho, la etimología de la mayólica (de maiorica, Mallorca)- y Nápoles, donde el Castel Nuovo lucía en la Sala de los Barones azulejos provenientes del Levante español. Esta cerámica, especialmente la valenciana, conocida como «loza de Valencia», fue muy apreciada por humanistas como Lucio Marineo Sículo, personaje importante en la corte de los hijos de los Reyes Católicos, donde también se crió el joven Garcilaso. Escribía Sículo, en el capítulo «De las vasijas y cosas de barro que en España se hazen» de su Obra de las cosas memorables de España (traducción de su Opus de rebus Hispaniae memorabilibus de I530):

Hazense también en España vasijas, y obras de barro de muchas maneras, y cosas de vidrio. Y aunque en muchos lugares de España son excelentes, las más preciadas son las de Valencia, que están muy labradas, y doradas. Y también en Murcia se hazen buenas desta misma arte. Y en Morviedro y en Toledo se haze, y labra mucho, y muy recio, blanco, y alguno verde, y mucho amarillo que paresce dorado; y esto es para servicio; porque lo mas preciado es lo que está vedriado de blanco. Tambien en Talavera se labra muy excelente vedriado blanco, y verde. Loqual es muy delgado y sotilmente hecho. Y hazense vasijas de muchas y diversas maneras. También en Malaga se hazen muy buenas. Y en Jaen ay buenas vasijas de toda suerte, y en Teruel se hacen muy excelentes, y mas hermosas que las otras (Marineo Sículo I539: lib. I, fol. $\left.\mathrm{v} \mathrm{v}^{\circ}\right)^{2}$.

Este tipo de cerámicas, que se puede vincular estéticamente con los cánones visuales del arte tardogótico -versión visual del arte de la poesía can-

2 También citado por Davillier (I86I : 32). 
cioneril-, también halla sus equivalentes en la producción italiana coeva, en diversos centros de producción, desde Venecia hasta Sicilia, con especial concentración en la Toscana, en Las Marcas y en Umbría, es decir, en una franja territorial al norte de los Estados pontificios: Faenza, Florencia, Montelupo, Siena, Deruta, Gubbio, Pesaro, Casteldurante o Urbino son, en este contexto, los nombres de los centros más significativos de la loza fina italiana a inicios del siglo XVI. Los motivos decorativos más frecuentes eran entonces motivos florales o abstractos, según se derivaran de una imitación de las formas tradicionales árabes o latinas. Otro tipo de motivos muy recurrente eran los perfiles de rostros, tanto masculinos como femeninos, por lo general inspirados en los retratos de personajes virtuosos de la Biblia o de la historia antigua.

Y es de subrayar que ya por aquel entonces se vislumbran vínculos entre alfarería y poesía, según atestigua por ejemplo una serie de platos probablemente producidos en Deruta y fechables entre I500 y I530, en los cuales se divisa el perfil de una donna modelo de virtud, con una filacteria cuyo texto consiste en un verso de Petrarca: «La vita el fin, e’l dí loda la sera», del verso 3I de la famosísima canzone Nel dolce tempo de la prima etade (Rvf XXIII) ${ }^{3}$. En otros casos, aun cuando no se identifica la relación con textos literarios concretos, se observa que la elección de las imágenes procede de una cultura aristocrática plasmada por la lectura de los buenos autores de la Antigüedad.

Los mismos temas seguían en uso cuando, durante los primeros años del Cinquecento, una serie de artistas italianos revolucionaron el arte de la loza fina italiana. Inventaron un nuevo tipo de decoración, llamado istoriato, que consistía en el uso de todo el plato pintado con una sola imagen ${ }^{4}$. Esta revolución se produjo en las mencionadas ciudades del centro-norte de la península italiana, principalmente en las cortes principescas de las Marcas, Emilia-Romania y Umbría -Urbino, Faenza y Deruta-. El uso de este tipo de cerámica bastante costosa quedaba reservado a las clases superiores de la sociedad, y sobre todo a la alta aristocracia. En palabras de Syson y Thornton, «la combinación virtuosa de elementos viejos y nuevos, tecnológicos y materiales, hizo de la mayólica istoriata un arte digno de atención por parte de los humanistas» (Syson y Thornton 200I: 222). Como tal, los artistas utilizaron todo un repertorio visual y simbólico que, en los mismos años, se difundió por toda Europa con el nuevo arte de la cortesanía

3 Se custodian actualmente ejemplares de este tipo en el neoyorkino Metropolitan Museum of Art (https://www.metmuseum.org/art/collection/search/I87831), en el Fitzwilliam Museum, Cambridge (http://webapps.fitzmuseum.cam.ac.uk/explorer/index.php?oid=47190), en el Musée national de la Renaissance, Ecouen ( $\mathrm{E} \mathrm{Cl} 2430$ ), así como, pero con un tipo de rostro femenino distinto de los tres anteriores, en el Museo Nazionale, Rávena.

4 El término aparece por primera vez hacia 1557, en un texto de Piccolpasso (ca. 1557: ms). 
que Baldasarre Castiglione estaba entonces definiendo en su Cortesano (I528) -diálogo ubicado en la corte de Urbino de inicios del Cinquecenco y con cuya reproducción en otras cortes toda la aristocracia soñaría durante las siguientes décadas.

El propio Garcilaso, quien releyó la traducción que su amigo Boscán hizo de El Cortesano (Barcelona, I534), difícilmente pudo sustraerse a la fascinación de esta nueva emanación del genio estético del Renacimiento italiano. De hecho, en el inventario post mortem de sus bienes (Toledo, I5 de enero de I537), se hallan, al lado de unos cuantos «vidrios de Venecia», "porcelanas de Venecia» y piezas «de barro colorado» (Sliwa 2006: I60). La distinción entre ambos tipos de cerámicas, entre porcelanas y barro colorado, dice bien el aprecio en que se tenían las primeras: cerámicas que, sin serlo realmente -la técnica de la porcelana verdadera solo se descubriría en Europa a inicios del siglo XVIII-, imitaban su impresionante blancura y, por tanto, se diferenciaban de las cerámicas más vulgares. La precisión «de Venecia» no remite necesariamente a su lugar de producción, puede designar, simplemente, el lugar de exportación de la loza: por Venecia transitaba el conjunto de la producción del noreste de la península italiana, hasta la de las Marcas. Resulta probable, pues, que Garcilaso poseyera entre sus bienes mayólica italiana, tal vez istoriata.

\section{2.}

Esta mayólica utilizó múltiples modelos visuales, en especial ediciones ilustradas de Ovidio de finales del siglo Xv, así como, en años más avanzados del Cinquecento, ediciones de las Metamorfosis de Lodovico Dolce (ca. I508-I568) o de Bernard Salomon (I506/IO-ca. I56I), o grabados de Hubertus Goltzius. Suele atribuirse un papel destacado en la difusión de la nueva tendencia a la ciudad de Urbino, patria de Rafael Sanzio. Tanto, que se llegó a pensar, durante el siglo XVII, que el mismo maestro habría realizado una serie de platos de especial valor visual5. Y es que el influjo de la obra del Urbinate en una serie de discípulos, especializados en el arte de la pintu-

5 Según la reconstrucción de Johanna Lessmann (I979: I2), esta leyenda parece hallar su origen en el juicio despreciativo formulado por Malvasia (I678: 47I), donde designa al pintor oriundo de Urbino como el alfarero de Urbino («boccalaio di Urbino»). Y es refutándolo que Vittoria (I703: II3-II4) menciona la existencia de una carta según la cual Rafael habría concebido una serie de esbozos para platos hechos para la duquesa de Urbino, lo cual no resultaría nada sorprendente. De ahí que, hablando de las colecciones de los duques de Braunschweig-Wolfenbüttel custodiadas durante los siglos XVII y XVIII en el palacio de Salzdahlum, el viajero Zacharias Konrad Uffenbach evocara que el guardamuebles (Bett-Meister) afirmara que los platos de la colección venían todos de la mano del mismísimo maestro: «Der Bett-Meister gab vor, daß sie alle von Raphael Urbino seyen, welches aber wegen der grossen Menge unglaublich, indem es wohl bey sechshundert Stücke waren...» (citado por Lessmann 1979: 14). 
ra de mayólicas, fue tal que puede considerarse que a partir de entonces la cerámica se convirtió en un canal privilegiado de la difusión de un nuevo imaginario visual creado a inicios del Cinquecento.

Descuellan en esta escuela los nombres de varios artistas, tanto por la calidad pictórica de su obra como por el uso sistemático de un corpus de representaciones mitológicas de raigambre esencialmente ovidiana. Entre ellos destaca Nicolás de Urbino (ca. I480-I540/I547), a quien se considera como el inventor del arte de la mayólica istoriata y se llegó a llamar el «Rafael de la mayólica». En una primera fase, recurrió para inventar la forma del plato istoriato a modelos visuales ya diseminados por la Europa de aquel entonces, en especial, a la edición ilustrada de las Metamorfosis (Venecia, I497) de Ovidio y, en un caso, a una imagen de la Hypnerotomachia Poliphilii $\left(\right.$ Venecia, I499) ${ }^{6}$. En un segundo momento, pasó a la imitación de los grabados de Marcantonio Raimondi, cuando no a la reutilización de dibujos de Rafael Sanzio (Ames-Lewis I988: 690-692). Resultó frecuente, asimismo, la inserción de blasones heráldicos en los platos, para relacionar las pinturas con el linaje nobiliario a cuyo uso las vasijas se destinaban. El conjunto que más fama adquirió es sin duda alguna la credenza, el conjunto de platos hecho hacia 523 para Isabella d'Este, marquesa de Mantua (I474-I539). El encargo lo hizo probablemente su hija Eleonora, después de haber residido durante varios años en Mantua, en la corte de su madre, junto con su esposo Francesco Maria della Rovere ${ }^{7}$. Este conjunto distaría sin embargo mucho de ser el único en salir del taller de Nicolás de Urbino, ya que se conocen conjuntos de platos realizados por el maestro hasta en I536, cuando entregó uno para Federico II Gonzaga, duque de Mantua - cuyo Palazzo del Te tanta impresión le había causado a la corte de Carlos V durante el viaje de coronación de 1530 .

Después de Nicolás de Urbino, es obligado aducir los nombres de Francesco Xanto Avelli, Guido di Merlino, Francesco Durantino, y otros. Destaca especialmente el primero de ellos, activo en Urbino entre 1530 y I542, por la calidad de sus pinturas, pero también por su vasta cultura literaria, que le permite enriquecer el registro de temas y formas de que se nutre el arte de la mayólica de su tiempo. Se le conoce también como poeta, en especial por la colección de cuarenta y cuatro sonetos reunidos en I537 en honor a Francesco Maria della Rovere, así como por otro poema anterior, hoy día perdido, Il Rovere vittorioso ${ }^{8}$. Merece realmente la designación como pintor

6 Plato de Salomón en adoración ante un ídolo, Museo Correr, Venecia.

7 Véase ahora la colección de estudios dedicados a esta fascinante credenza: Ferrari y Palvarini Gobio Casali (2014) y Boutin Vitela (20II).

8 Se le conoce por un plato conservado en el British Museum (Londres), pintado «en Urbino», en I532, con una alegoría cuyo sentido se explica mediante una inscripción cuyo fin reza: «Nel.XXV canto del Rovere vittorioso, di. F.X.A.R. pictor». Sobre Francesco Xanto Avelli, véase el 
docto, ya que, gracias a su saber humanístico, eleva la cerámica al rango de un arte hermana de la pintura, con una igual capacidad de representar la istoria y las fábulas, inspirándose en auctores antiguos -Virgilio, Ovidio, Livio, Valerio Máximo, Pompeyo Trogo, Justino, la Biblia-, así como modernos Petrarca y Ariosto, cuyos versos copia a menudo en el envés de sus platos-. Al igual que en el caso de Nicolás de Urbino, se conocen de Francesco Xanto Avelli credenze impresionantes, como la que hiciera en $\mathrm{I} 532 / 33$ para un comitente desconocido - cuyas armas parecen ser las de los Pucci florentinos: una cabeza de moro con una cinta en la frente- y de la que se conservan nada menos que treinta y siete piezas ${ }^{9}$.

Según el recuento de Alison Holcroft, Avelli utiliza al menos cinco veces pasajes de Ariosto, principalmente entre I53I y I532. Pero es Petrarca quien, en especial, le sirve a Avelli como autoridad poética moderna, detalle que no sorprende en lo más mínimo, dado que el periodo de su actividad se corresponde con los años de mayor intensidad de la moda del petrarquismo italiano. Holcroft señala al menos tres, si no cuatro platos con citas de los Rerum vulgarium fragmenta ${ }^{\mathrm{IO}}$, así como unos diez con los Triumphi del poeta toscano. Resulta interesante, además, ver que algunas citas de los Triumphi -obra que brinda a sus lectores un amplio repaso por las figuras estelares de la Antigüedad- se esconden detrás de otras referencias, como es el caso de un caso que parece remitir a Pompeyo Trogo (Holcroft I988). Las escenas representadas en dichos platos remiten a hitos de la historia o de la mitología antigua: I. Eneas, Anquises y Ascanio; 2. Helena; 3. Anfiarao; 4. Píramo y Tisbe; 5. Hero y Leandro; 6. Narciso; 7. Lucrecia; 8. Judit; 9. Mucio Escévola; Io. Semíramis. Los temas así figurados en las mayólicas de Urbino-como en las de otros centros de cerámica contemporáneos- pertenecen a una suerte de common knowledge literario teñido de reminiscencias humanísticas, difundido por toda Europa gracias al papel divulgativo de una obra como los Triumphi, que también podía funcionar a modo de enciclopedia poética de la Antigüedad ${ }^{\mathrm{II}}$.

Lo interesante, en este contexto, es que Avelli colocara en el envés de sus platos citas de los Triumphi. Estas suelen empezar con un tipo de fór-

clásico Vitaletti (I9I2), así como, ahora, Mallet (2007). Sobre las fuentes literarias de sus platos, Ballardini Napolitani (1940).

9 Se custodian ejemplares en New York, Cleveland, Washington, Londres, Cambridge, San Petersburgo y París.

Io Se conserva así, en el Louvre (París), un plato en cuyo envés se citan los versos del soneto I36 de los Rerum vulgarium fragmenta: «Fiamma dal Ciel su le tue treccie piova,/ malvagia che dal fiume et da le ghia [n] dep [er] laltrui impoverir». Se halla una descripción del plato - que pertenece a la antes mencionada credenza con armas de los Pucci- en Giacomotti (1974: 263-264). Véase también: https://www.louvre.fr/en/oeuvre-notices/dish-arms-pucci-family-florence.

II Sobre la difusión de los Triumphi en Europa a inicios del siglo XVI, véase ahora el número monográfico editado por Valero Moreno (2015). 
mulas recurrentes, o bien con demostrativos ("Questo è...», «Ecco...», etc.), o bien con el uso de verba videndi, en presente («Vedi...») o en pretérito («Vidi...»). A menudo el pintor retoma ne varietur la fórmula de los Triumphi, a veces la adapta -por ejemplo, cuando cambia «L'altro è colui» por "Quest'è colui...» (Holcroft 1988: 226). Y es que Avelli no hace sino aprovecharse de que los Triumphi no son sino «lunghe pitture», es decir, una impresionante sucesión de cuadros que ve el espectador -el sujeto que experimenta la visión profética que recibe mientras duerme. La omnipresencia de los verba videndi en los Triumphi deriva por tanto del proyecto, de clara inspiración medieval, de la descripción de los personajes salidos de la Antigüedad. Al desgajar estos, sin embargo, de este contexto, y quedándose tan solo con las unidades visuales introducidas por un demostrativo o un verbo que expresa el acto de la visión, los intérpretes del Cinquecento aprovechan esta estructura medieval para sacar a lucir los momentos visualmente más elocuentes. Un proceso semejante se da, de hecho, con la famosa Canzone delle visioni del mismo Petrarca, donde el sujeto también ve aparecer, ante sus ojos maravillados, una serie de visiones en relación con su pasión amorosa. Varios manuscritos evidencian el fuerte potencial visual de estas imágenes que, pesa a su condición lírica, suscitaron numerosas traducciones ilustradas en los márgenes de los manuscritos ${ }^{12}$.

\section{3.}

Muchas imágenes del imaginario petrarquesco derivan, como es obvio, del vasto thesaurus mitográfico heredado, directa o indirectamente, de las Metamorfosis ovidianas. Y no sorprende, por tanto, que la fórmula «vidi» se haya trasladado a la evocación de escenas derivadas de Ovidio, que se habían convertido en motivos visuales predilectos de las mayólicas renacentistas. Los platos de este tipo representaban, daban a ver las escenas de Ovidio, como lo subrayaban también los textos que acompañaban a menudo estas escenas y que los pintores escribían debajo del plato. «Vedi Ovidio», reza así un plato conservado en Braunschweig, que representa a Juno metamorfoseando en vaca a Ío (Lessmann i979: num. cat. 316).

Frente a esta difusión de los verba videndi, como intermedios entre la escena representada y el ojo del espectador, que también es lector, la poesía a su vez renueva el estatuto del objeto visual propuesto a la visión del lector. Este es, en especial, el caso de la obra poética de Garcilaso de la Vega, como lo pueden sugerir dos ejemplos que ahora se considerarán.

Recuérdese el famosísimo soneto XIII del toledano:

I2 Andrea Torre ha dedicado toda una serie de trabajos sobre las visualizaciones de los Rerum vulgarium fragmenta; véase en especial Torre (2012). 
A Dafne ya los brazos le crecían y en luengos ramos vueltos se mostraban; en verdes hojas vi que se tornaban los cabellos qu'el oro escurecían;

de áspera corteza se cubrían los tiernos miembros que aun bullendo 'staban; los blancos pies en tierra se hincaban y en torcidas raíces se volvían.

Aquel que fue la causa de tal daño, a fuerza de llorar, crecer hacía este árbol, que con lágrimas regaba.

¡Oh miserable estado, oh mal tamaño, que con llorarla crezca cada día la causa y la razón por que lloraba (I995: 34).

Mucho ya se ha escrito sobre el soneto y su relación con el mundo visual del Renacimiento. Se ha destacado, en especial, el papel de los grabados de la escuela de Marcantonio Raimondi y de Agostino Veneziano en la difusión de tipos iconográficos a los que el soneto de Garcilaso podría hacer referencia, y se ha destacado, asimismo, la cercanía entre este tipo de descripción poética y los esfuerzos, en los círculos de Isabella d'Este, de reconstruir el mundo de la pintura clásica a partir de las ekphraseis clásicas ${ }^{13}$.

Otro detalle ha suscitado el interés de la crítica: la presencia del sujeto mediante el verbum videndi «vi», ausente de la descripción que da Ovidio de la escena en sus Metamorphosis. Para unos, como Fernando de Herrera, no pasa de ser una muletilla poética ${ }^{14}$, mientras que para otros podría significar que el sujeto poético y, quizás, Garcilaso, se habría de identificar con Apolo. Como ya observaba Ignacio Navarrete, la formula «vi», en el contexto que nos interesa, es de gusto típicamente petrarquesco:

The key here is the word «saw», «en verdes hojas vi que se tornavan». Herrera, the only one of Garcilaso's Renaissance annotators to comment on the word, thought its only purpose was to fill out the line (349). Yet its use also recalls several key lines of Petrarch's, including the idolatrous sestina 30 «Giovane donna sotto un verde lauro / vidi» (A young woman beneath a green laurel / I saw, Rime sparse 30.I-2), and canzone 23 itself, «e i capei vidi far di quella fronde» (and hair I saw turned into those leaves, 43). But in the can-

I3 Véanse, para cada uno de estos aspectos, Escobar Borrego (200I) y García-Bermejo Giner (2005).

I4 (Herrera 200I: 366): «A mi parecer, solo sirve este verbo de sustentar el verso. Pero puede tolerarse por causa de elegancia, i ser figura [...]». 
zone Petrarch sees his own transformation, while in Garcilaso's sonnet the object of his vision is not the poet himself. He may be describing a painting, which would link this poem to his many ekphrastic compositions, particularly the third eclogue (see Lapesa, I64-65). But he also figures himself as Apollo the pursuer (see Barnard, The Myth, II5-I6), putting the poet -and by extension the reader- directly in Apollo's place, seeing the transformation as he saw it and feeling his frustration (Navarrete 1994: 97-98).

De por sí, en realidad, la fórmula vidi es una fórmula típica de cualquier literatura de visión, especialmente en boga durante la Edad media y en cuyas múltiples fuentes bebió el poeta de Laura. Según se ha visto, también era omnipresente en los Triumphi de Petrarca y, como tal, se había multiplicado como fórmula de presentación de escenas mitológicas presentadas ante la mirada del poeta visionario. Cabría suponer, pues, que lo que Garcilaso expresa con el uso de este verbum videndi es una fórmula tópica de este género pictórico menor que es la mayólica, donde se registran por otro lado muchos casos de representación del mito de Apolo y Dafne. ${ }^{15}$.

Otro ejemplo de esta posibilidad de leer los sonetos de Garcilaso que describen escenas mitológicas como equivalentes verbales de los platos de mayólica italianos de su tiempo lo brinda el soneto XXIX. Este poema pinta con pathos la porfía y la muerte del joven Leandro, a punto de anegarse en las aguas del Helesponto:

\author{
Pasando el mar Leandro el animoso, \\ en amoroso fuego todo ardiendo, \\ esforzó el viento, y fuese embraveciendo \\ el agua con un ímpetu furioso. \\ Vencido del trabajo presuroso, \\ contrastar a las ondas no pudiendo, \\ y más del bien que allí perdía muriendo, \\ que de su propia muerte congojoso, \\ como pudo, 'sforzó su voz cansada \\ y a las ondas habló d'esta manera, \\ mas nunca fue su voz dellas oída:
}

I5 Recuérdese tan solo, por ser contemporánea de Garcilaso, la saliera, hoy día custodiada en Dresde (inventario, $\mathrm{n}^{\circ}$ 38532). Realizada hacia $1530 / 40$ en Urbino por Guido di Merlino, para Helena Schellenberger, la rica viuda de Hans Herwart (Augsburgo), es el caso perfecto de encargo de un conjunto de loza fina para clientes cultos admiradores del arte italiano, mucho más allá de los confines de la península italiana (cf. Richter 2006: 140). 
Ondas, pues no se escusa que yo muera, dejadme allá llegar, y a la tornada vuestro furor esecutá en mi vida» (59).

Ahora bien, como ya analizamos en otros lugares (Béhar 2015 y 2016), el soneto no sólo reescribe un celebérrimo epigrama de Marcial ( Clamabat tumidis audax Leander undis / Parcite dum propero, mergite dum redeo») y adapta los dos grabados que adornaban la edición aldina del epilio Leandro de Museo, sino que también se puede entender como una respuesta a la gran difusión del verso de los Triumphi de Petrarca donde se veía a «Leandro in mare et Ero a la fenestra» (Triumphus Cupidinis, II, 2I). En efecto, la fórmula tópica resume la escena y múltiples poetas y artistas la aprovecharán para imitarla. Si bien Gutierre de Cetina, en un soneto algo más tardío, se centrará en su soneto CXIV en «Hero [...] esperando a la fenestra» (Béhar $2015 \mathrm{y}$ 20I6), Garcilaso, por su parte, prefiere describir, para conservar las palabras de Petrarca, a «Leandro in mare».

En este sentido, se puede afirmar que su soneto XXIX se corresponde con mayólicas contemporáneas con el mismo tema explícitamente inspiradas en Petrarca, como las de Francesco Xanto Avelli -en especial, una de I540, con la cita explícita del verso de los Triumphi ${ }^{16}$. El pintor de Urbino ha elaborado la representación de la escena a partir de distintos préstamos: Hero está copiada en las Menadas del monogramista PP, Leandro en la Escena de batalla de Agostino Veneziano, imitada de Giulio Romano, y el pequeño Cupido, en la Alegoría de la Caridad de Marcantonio Raimondi, copia de Rafael Sanzio.

Este segundo ejemplo sugiere que los modelos que pudieron inspirar a Garcilaso son probablemente múltiples y que, si bien el poeta pudo pensar en algún grabado para su evocación de la escena, tampoco debería descartarse el estímulo visual de las elegantes piezas de mayólica de Urbino, exquisito objeto de colección en las cortes europeas, de las que acaso el poeta toledano poseyera algunos ejemplares (recuérdense las «cuatro porcelanas de Venecia» del inventario de sus bienes). De modo comparable a lo que se observa con los grabados, las mayólicas combinan modelos visuales y crean un nuevo lenguaje, derivado en lo esencial de la magistral renovación del repertorio pictórico llevada a cabo por Rafael de Urbino: asimismo tanto en lo épico como en lo mitológico, el gran pintor inspira profundamente al joven poeta de Toledo fascinado por la Italia de su tiempo ${ }^{17}$.

I6 Francesco Xanto Avelli, plato de I540, con el verso «Leandro i mare, et / Ero alla finestra», en el envés. El plato pertenece ahora a la Fondazione Banca del Monte di Rovigo, y se conserva en el Museo dei Grandi Fiumi, en Rovigo; véase http://www.fondazionebancadelmonte.rovigo. it/ero-e-leandro-2/.

I7 Sobre el papel de Rafael para el repertorio épico, véase el ya citado Béhar (2017b). 


\section{Bibliografía}

Ames-Lewis, Francis, «Nicola da Urbino and Raphael», The Burlington Magazine, 130/1026, 1988, pp. 690-692.

Ballardini Napolitani, Dora, «Ispirazioni e fonti letterarie nell'opera di Francesco Xanto Avelli pittore su maiolica in Urbino», La Rinascita, III, I940, pp. 905-922.

Béhar, Roland, «Galatea, o la idea de la belleza garcilasiana», Bulletin hispanique, II9/2, 20I7a, pp. 59I-620.

-. «La gloria de don Fernando: el valor épico de la representación escultórica en la Égloga II de Garcilaso de la Vega», en La estirpe de Pigmalión: poesía y escultura en el Siglo de Oro, eds. Marcial Rubio Árquez y Adrián J. Sáez, Madrid, Sial Ediciones, 2017b, pp. 63-99.

- «Cum peteret dulces audax Leandros amores...: Lectures européennes d'une épigramme de Martial, entre 1530 et I550", en Paroles dégelées - Propos de l'Atelier XVI e siècle, eds. Isabelle Garnier et. al., París, Classiques Garnier, 2016, pp. 29-50.

—. «Musœum ante omnes...: la fortune critique de Musée dans la théorie poétique espagnole du Siglo de Oro», e-Spania, 2I, 2015: http://journals.openedition.org/e-spania/246I5; DOI: I0.400o/e-spania.246I5.

Boutin Vitela, Lisa, Displaying Identity in the Mantua Court: The Maiolica of Isabella d'Este, Federico II Gonzaga, and Margherita Paleologa, PhD diss., Los Angeles, University of California, 20II.

Cetina, Gutierre de, Rimas, ed. Jesús Ponce Cárdenas, Madrid, Cátedra, 20I4, pp. 432-433.

Davillier, Jean-Charles, Histoire des Faïences hispano-moresques à reflets métalliques, París, Librairie Archéologique de Victor Didron, I86I.

Escobar Borrego, Francisco Javier, «El tema de Apolo y Dafne en Garcilaso de la Vega: Paralelos pictóricos», Calamus Renascens. Revista de Humanismo y Tradición Clásica, 2, 200I, pp. 223-238.

Ferrari, Daniela \& Mariarosa Palvarini Gobio Casali (eds.), Una «credenza» istoriata per Isabella d'Este. Il servizio di Nicola d'Urbino interpretato da Ester Mantovani, Mantua, Universitas Studiorum, 2014.

García-Bermejo Giner, Miguel, «El trasfondo literario y artístico del soneto XIII de Garcilaso», en Nápoles-Roma, I504. Cultura y literatura española y portuguesa en Italia en el quinto centenario de la muerte de Isabel la Católica, eds. Folke Gernert y Javier Gómez-Montero, Salamanca, SEMYR, 2005, pp. 335-347.

Giacomotti, Jeanne, Catalogue des majoliques des musées nationaux: musées du Louvre et de Cluny, Musée national de céramique à Sèvres, Musée Adrien-Dubouché à Limoges, París, Éditions de la Réunion des musées nationaux, I974. 
Herrera, Fernando de, Anotaciones a la poesía de Garcilaso, eds. Inoria Pepe y José Maria Reyes, Madrid, Cátedra, 2001.

Holcroft, Alison, «Francesco Xanto Avelli and Petrarch», Journal of the Warburg and Courtauld Institutes, 5I, I988, pp. 225-234.

Lessmann, Johanna, Italienische Majolika, Braunschweig, Herzog Anton-Ulrich Museum, 1979.

Mallet, J.V.G., Xanto: Pottery-painter, Poet, Man of the Italian Renaissance, catalogo della mostra, Londres, The Wallace Collection, 2007.

Malvasia, Carlo Cesare, Felsina Pittrice. Vite dei pittori Bolognesi, Bolonia, Gio. Francesco Davice, 2 vols., I678.

Marineo Sículo, Lucio, De las cosas memorables de España, Alcalá de Henares, Juan de Brocar, I539.

Navarrete, Ignacio, Orphans of Petrarch: Poetry and Theory in the Spanish Renaissance, Berkeley, University of California Press, I994. http://ark.cdlib. org/ark:/13030/ft30000518/.

Piccolpasso, Cipirano, Li tre libri dell'arte del vasaio, ca. I557, ms. Londres, National Library, Victoria and Albert Museum, MSL/I86I/7446.

Richter, Rainer (ed.), Götter, Helden und Grotesken. Das Goldene Zeitalter der Majolika, Múnich, Hirmer Verlag, 2006.

Sliwa, Krzysztof (ed.), Cartas, documentos y escrituras de Garcilaso de la Vega y de sus familiares, Alcalá de Henares, Centro de Estudios Cervantinos, 2006.

Syson, Luke \& Dora Thornton, Objects of Virtue. Art in Renaissance Italy, Los Angeles, The J. Paul Getty Museum, 200I.

Torre, Andrea, «The Window and the Diamond. Reading, memorizing and visualizing Petrarch's Rerum Vulgarium Fragmenta", Nottingham Medieval Studies. Inventing a Path. Studies in Medieval Rhetoric in Honour of Mary Carruthers, LVI, 20I2, pp. 35I-376.

Valero Moreno, Juan Miguel (ed.), Quaderns d'Italià, Petrarca y el humanismo en la península Ibérica, 20, 20I5. https://ddd.uab.cat/search?cc=qdi\&f=issue\&p=qdi_a20I5n2o\&rg=Ioo\&sf=fpage \&so=a\&ln=ca.

Vega, Garcilaso de la, Obra poética, ed. Bienvenido Morros, estudio preliminar de Rafael Lapesa, Barcelona, Editorial Crítica, I995.

Vitaletti, G., Francesco Xanto Avelli, Urbino, s.n., I9I2.

Vittoria, Vincenzo, Osservazioni sopra il libro della Felsina pittrice per difesa di Raffaello da Urbino, dei Caracci e della loro scuola, Roma, Gaetano Zenobi, I703. 